\title{
KEBIJAKAN PENGELOLAAN LIMBAH PADAT BUKAN BERASAL DARI BAHAN BERBAHAYA DAN BERACUN MELALUI RE-USE ATAU RE-CYCLING UNTUK KELESTARIAN LINGKUNGAN HIDUP
}

\author{
Muhamad Ibnu Fajar ${ }^{1}$ Nadiroh $^{2}$ Muzani $^{3}$ \\ ${ }^{I}$ Manajemen Lingkungan, Pascasarjana Universitas Negeri Jakarta \\ ${ }^{2}$ Pendidikan PPKn, Fakultas Ilmu Sosial, Universitas Negeri Jakarta, ${ }^{3}$ Program Studi Geografi, Fakultas \\ Ilmu Sosial, Universitas Negeri Jakarta
}

\begin{abstract}
Abstrak
Penelitian ini bertujuan untuk menjelaskan tentang kebijakan pengelolaan limbah padat bukan berasal dari bahan berbahaya dan beracun melalui re use atau re cycling untuk kelestarian lingkungan. Kebijakan ini telah tertuang dalam peraturan pemerintah daerah kabupaten Bekasi Nomor 09 Tahun 2007. Kebijakan ini merupakan sebuah upaya didalam pengelolaan limbah non B3 agar menjadi tertib dan bebas dari lingkungan yang kotor bahkan kumuh. Melalui kebijakan ini pengelola limbah diwajibkan untuk terdaftar dalam perizinan perusahaan pengelola limbah khusunya limbah padat non B3. Penelitian ini menggunakan metode kualitatif dengan pertimbangan, peneliti menggunakan angket sebagai bahan pertimbangan menentukan skala presentase keberhasilan kebijakan pengelolaan limbah. Bedasarkan hasil analisis kebijakan pengelolaan limbah padat bukan berasal dari bahan berbahaya dan beracun melalui re use atau re- cyling untuk kelestarian lingkungan memperoleh hasil yang dikonversikan dalam kualitatif termasuk kategori tinggi dan sangat baik.
\end{abstract}

Kata Kunci : Kebijakan Pengelolaan Limbah. Pengelolaan Limbah.

\begin{abstract}
Abstrak
This study aims to explain the policy of managing solid waste not from hazardous and toxic materials through re-use or re-cycling for environmental sustainability. This policy has been contained in the Bekasi district government regulation Number 09 of 2007. This policy is an effort in the management of non-B3 waste in order to become orderly and free from dirty and even slums. Through this policy the waste manager is required to be registered in the licensing of the waste management company, especially non-B3 solid waste. This study uses qualitative methods with consideration, researchers use questionnaires as consideration for determining the percentage scale of the success of waste management policies. Based on the results of the analysis of policies on the management of solid waste not to preserve the environment, the results were converted into qualitative, including high and very good categories.
\end{abstract}

Keywords: Waste Management Policy. Waste Management. 


\section{PENDAHULUAN}

Sesuai dengan sifatnya, limbah padat dapat dikelompokkan atas limbah padat yang berasal dari bahan berbahaya dan beracun (limbah padat B3) serta limbah padat bukan berasal dari bahan berbahaya dan beracun (limbah padat non B3). Secara umum, pengelolaan limbah bukan Bahan Berbahaya dan Beracun termasuk limbah padat bukan Bahan Berbahaya dan Beracun adalah dengan melakukan upaya recovery, termasuk re-use dan re-cycling sebagai bentuk upaya recovery yang dilakukan terhadap limbah padat bukan Bahan Berbahaya dan Beracun. Tentang hal itu, Enri Damanhuri dan Padmi menyebutkan bahwa : Recovery :upaya untuk memberikan nilai kembali limbah yang terbuang, sehingga bisa dimanfaatkan kembali dalam berbagai bentuk, melalui upaya pengumpulan dan pemisahan yang baik. Reuse: upaya yang dilakukan bila limbah tersebut dimanfaatkan kembali tanpa mengalami proses atau tanpa transformasi baru, misalnya botol minuman kembali menjadi botol minuman. Recycle: upaya untuk mendapatkan sesuatu yang berharga dari sampah dan limbah. Misalnya botol minuman dilebur namun tetap dijadikan produk yang berbasis pada gelas. Bisa saja terjadi bahwa kualitas produk yang baru sudah mengalami penurunan dibanding produk asalnya. Kosa kata inilah yang paling sering digunakan. Mungkin dalam bahasa Indonesia kosa kata yang sepadan adalah daur-ulang (Damanhuri \& Padmi, 2010).

Pengelolaan limbah padat bukan Bahan Berbahaya dan Beracun adalah terutama dengan melakukan recovery, melalui reuse dan recycling limbah padat bukan Bahan Berbahaya dan Beracun menjadi kebutuhan terutama pada wilayah yang merupakan sumber limbah tersebut. Wilayah yang merupakan sumber limbah padat bukan Bahan Berbahaya dan Beracun dan membutuhkan pengelolaan melalui reuse dan recycling limbah padat bukan Bahan Berbahaya dan Beracun, terutama adalah wilayah yang memiliki banyak industri dan adanya kawasan industri yang rentan untuk menghasilkan limbah termasuk limbah padat bukan Bahan Berbahaya dan Beracun. Karena itu melakukan pengelolaan limbah melalui reuse dan recycling terhadap limbah padat bukan Bahan Berbahaya dan Beracun adalah pengelolaan limbah yang seharusnya dilakukan di wilayah tersebut, agar limbah padat bukan Bahan Berbahaya dan Beracun tidak mengganggu lingkungan disekitarnya. Pengelolaan limbah melalui reuse dan recycling terhadap limbah padat bukan Bahan Berbahaya dan Beracun menjadi 
kebutuhan terutama di wilayah yang merupakan sumber limbah, termasuk di Kabupaten Bekasi sebagai wilayah dengan pertumbuhan industri yang tinggi.

Sebagai suatu kebijakan publik, Peraturan Daerah Kabupaten Bekasi Nomor 9 Tahun 2007 tentang Izin Pengelolaan Limbah Padat Bukan Bahan Berbahaya dan Beracun (Non B3) yang Bernilai Ekonomis adalah kebijakan yang direncanakan sebagai program yang disiapkan untuk dilaksanakan dan diimplementasikan. Sebagai kebijakan publik yang telah dilahirkan semenjak 2007,maka implementasi Peraturan Daerah Kabupaten Bekasi Nomor 9 Tahun 2007 merujuk pada implementasi kebijakan publik pada umumnya.

\section{KEBIJAKAN}

Pemaknaan kata kebijakan (policy) dalam rujukan definisi dapat diklasifikasikan dalam dua pemahaman umum tentang apa itu kebijakan. Kedua pemahaman itu saling berhubungan karena berkaitan dengan apa yang dimaksudkan dengan kebijakan dan bagaimana kebijakan dilahirkan. Stanley (2010) menyebutkan bahwa : The first view is that policy is the result of authoritative choice, whereby governments make policy through a vertical, hierarchical process in which a government minister determines the eventual outcome. This is the classical view of public policy that dominates the field of policy studies. The second view is that policy is the result of structured interaction, produced through complex horizontal relationships in which the end result is the product of compromise and the accommodation of competing interests. Pandangan pertama adalah bahwa kebijakan merupakan hasil dari pilihan yang otoritatif, dimana pemerintah membuat kebijakan melalui proses hirarki vertikal dengan mana seorang menteri pemerintah menentukan hasil akhirnya. Ini adalah pandangan klasik dari kebijakan publik yang mendominasi kajian studi kebijakan. Pandangan kedua adalah bahwa kebijakan merupakan hasil dari interaksi terstruktur, yang dihasilkan melalui hubungan horizontal yang kompleks di mana hasil akhirnya adalah produk yang bersifat kompromi dan mengakomodasi persaingan kepentingan.

Dengan adanya dua pandangan tentang makna kebijakan maka kedua pandangan itu merupakan pandangan yang saling melengkapi, sehingga makna kebijakan akan merujuk pada model sesuai dengan pandangan (views) yang digunakan. Dengan menggunakan model yang disederhanakan tentang makna kebijakan. 
ELmakki (2006) menyebutkan bahwa : Policies usually involve a series of interrelated decisions; rather than a single decision-maker, many different people at different levels and scattered throughout government organizations make public policy decisions; policies are shaped by earlier policy decisions and environmental factors; policies are mediated through their implementation; policies involve both actions and inactions; policies cannot be analysed apart from the policy making process; policies have outcomes that may or may not have been foreseen; policies are subjectively defined, and may be defined retrospectively; policies extend beyond the formal records of decisions; and policies need resources and action to be differentiated from political rhetoric.

Kebijakan biasanya melibatkan serangkaian keputusan yang saling terkait dari pembuat keputusan tunggal, banyak orang yang berbeda pada tingkat yang berbeda dan tersebar di seluruh organisasi pemerintah yang membuat desisi kebijakan publik; kebijakan dibentuk oleh desisi kebijakan sebelumnya dan faktor lingkungan; kebijakan dimediasi melalui implementasinya; kebijakan melibatkan aksi dan tidak beraksi; kebijakan tidak dapat dianalisis terpisah dari proses pembuatan kebijakan; kebijakan memiliki hasil yang mungkin atau tidak mungkin dapat diramalkan; kebijakan adalah pendefinisian yang subyektif, dan dapat didefinisikan secara retrospektif; kebijakan melampaui catatan formal keputusan; dan kebijakan membutuhkan sumber daya dan tindakan untuk membedakannya dari retorika politik.

\section{KEBIJAKAN \\ PENGELOLAAN LIMBAH}

Dalam hubungannya dengan pengelolaan limbah padat non B-3, apakah kebijakan ini berjalan sesuai dengan pedoman pelaksanaannya dan mencapai sasaran dan tujuan yang seharusnya dicapai, maka akan dibandingkan antara tujuan formal kebijakan dengan realita atau prestasi yang dicapai. Pada sisi lainnya, konsekuensi dari suatu kebijakan apabila telah diimplementasikan biasanya membawa perubahan sosial ekonomi yang berkenaan dengan atau dalam batas-batas antara kemanfaatan yang diakibatkan oleh efek yang terjadi, dan konsekuensi ini berupa dampak kebijakan. Dampak mempunyai arti tubrukan, benturan, pengaruh. Sedangkan di dalam Kamus Besar Bahasa Indonesia, dampak diartikan sebagai benturan, pengaruh kuat yang mendatangkan akibat (baik positif maupun negatif). Willliam N. Dunn mendefinisikan dampak sebagai perubahan kondisi fisik maupun sosial sebagai akibat dari output 
kebijakan (Dunn, 2015). Irfan Islamy menyebutkan pengertian dampak kebijakan adalah akibat-akibat dan konsekuensi-konsekuensi yang ditimbulkan dengan dilaksanakannya kebijakan (Islamy, 1997).

\section{METODOLOGI PENELITIAN}

Penelitian ini dilaksanakan pada bulan Januari hingga April 2018 menggunakan pendekatan kualitatif dengan desain deskriptif. Pendekatan kualitatif adalah hal-hal yang berkenaan dengan metode-metode kualitatif, baik tinjauan konseptual maupun aspek praktis pengambilan data dan langkah analisisnya. Alasan untuk melakukan penelitian kualitatif adalah bahwa penelitian tersebut bersifat penyelidikan, topik atau populasi yang diteliti belum banyak ditulis, dan peneliti harus mendengarkan informasi dari informan dan membuat gambaran berdasarkan keterangan informan.

\section{HASIL DAN PEMBAHASAN}

1. Perencanaan Pengelolaan Limbah Padat Non B-3 Melalui Re-Use Atau Re-Cycling Untuk Kelestarian

\section{Lingkungan Hidup}

Masyarakat mempunyai kesempatan yang sama dan seluas luasnya untuk berperan dalam pengelolaan lingkungan hidup. Individu maupun masyarakat wajib untuk menjaga kelestarian lingkungan hidup yang dapat berdampak luas kepada masyarakat apabila diabaikan dan tidak menjadi perhatian bersama dalam penanggulangan terhadap dampak lingkungan. Dalam hal pengelolaan limbah padat non B3, perusahaan industri yang bergerak dalam bidang pengelolaan limbah, melakukan kegiatan industri tersebut bedasarkan peraturan daerah yang telah dibuat. Adapun langkah-langkah dalam rencana pengelolaan limbah padat nonB3 yaitu :

a. Menganalisis limbah padat yang ditimbulkan di suatu kota untuk mendapatkan perkiraan limbah padat yang akan dikelola.

b. Menganalisis karakteristik limbah padat yang dihasilkan. Karakteristik limbah padat dilihat dari komposisi fisik dan komposisi kimia. Karakteristik limbah padat secara fisik dibedakan menjadi:

- Jenis komponen

- Sifat masing-masing komponen yang terdiri dari ukuran butir, dan kadar air

- Rapat massa

Sedangkan karakteristik kimia dibedakan menjadi:

- Kandungan energi 
- Kandungan kimia seperti Carbon, Hidrogen, Oksigen, dan Belerang.

Informasi tentang karakteristik limbah padat diperlukan untuk:

- Pemilihan peralatan, sistem, program dan rencana pengelolaan, pemilihan bahan-bahan yang bisa digunakan kembali dan pemanfaatannya untuk sumber energy

- Analisis serta perencanaan tempat pembuangan akhir (TPA)

c. Melakukan penilaian terhadap kondisi daerah yang direncanakan dengan analisis

d. Fungsi dan Nilai Kawasan : apakah kawasan tersebut adalah kawasan perumahan teratur dan tidak teratur, kawasan komersial atau kawasan perdagangan, kawasan indstri, perkantoran, pendidikan, dan kondisi jalan protokol, taman-taman kota dan hutan kota.

e. Kepadatan Penduduk : apakah berkepadatan rendah $(<100 \mathrm{jiwa} / \mathrm{Ha})$, kepadatan sedang (100-300 jiwa/Ha), kepadatan tinggi (>300 jiwa/Ha)

f. Kondisi Lingkungan : penilaian terhadap kondisi eksisting terhadap pengelolaan limbah padat

- Baik, bila limbah padat dikelola dan lingkungan menjadi bersih
- Sedang, bila limbah padat dikelola tapi lingkungan masih kotor

- Buruk, bila limbah padat tidak dikelola dan lingkungan masih kotor

- Buruk sekali, bila limbah tidak dikelola dan lingkungan sangat kotor

g. Daerah Pelayanan melihat kondisi pelayanan sampah eksisting di daerah sekitar

h. Tingkat Pendapatan Penduduk (rendah, sedang atau tinggi)

i. Tipografi (datar, bergelombang atau berbukit)

j. Menentukan tingkat pelayanan yang akan diberikan, antara lain dengan menentukan:

- Strategi Pelayanan

- Frekuensi Pelayanan

k. Wilayah dengan pelayanan intensif: pusat kota, jalan protokol, taman / hutan kota, kawasan pemukiman tidak teratur, dan pusat perdagangan termasuk pasar

1. Wilayah dengan pelayanan menengah: wilayah pemukiman teratur, komplek pendidikan / perkantoran, komplek kesehatan dan industry

m. Wilayah dengan pelayanan rendah yaitu wilayah pinggir kota

n. Kualitas Operasional 
- Penggunaan jenis peralatan

- Sampah yang terisolasi dari lingkungan

- Frekuensi pelayanan

- Frekuensi penyapuan jalan

- Estetika

- Tipe kota

- Variasi daerah pelayanan

- Pendapatan dari retribusi limbah padat

- Timbunan limbah padat

o. Merencanakan kebutuhan peralatan untuk pengelolaan sampah atau limbah padat yaitu:

- Peralatan sub-sistem pewadahan, seperti: bak sampah dari beton, ada yang dari tong yang terbuat dari seng, plastik, dll atau ada yang menggunakan container.

- Peralatan sub-sistem pengumpulan

1. Pengumpulan individual tidak langsung, maksudnya adalah kendaraan pengumpul (gerobak) mengambil timbulan sampah langsung dari pengguna jasa, misalnya: rumah tangga. Kemudian diangkut ke transfer depo (stasiun
2. pemindahan) lalu dibawa oleh kendaraan pengangkut (truk) untuk dibuang ke tempat pembuangan akhir (TPA).

Biasanya pengumpulan ini digunakan apabila kendaraan pengangkut tidak dapat mengambil secara langsung ke pengguna jasa.

3. Pengumpulan individual langsung, maksudnya adalah kendaraan pengangkut (truk) langsungmengambil timbulan sampah dari pengguna jasa untuk kemudian dibuang ke TPA.

4. Pengumpulan komunal langsung, maksudnya pengguna jasa mengumpulkan sampah secara komunal pada wadah komunal untuk dibawa oleh kendaraan pengumpul, kemudian dibawa ke transfer depo, lalu diangkut oleh kendaraan pengangkut untuk dibuang ke TPA. Sama seperti No 1 dimana kendaraan pengangkut tidak dapat mengambil secara langsung ke pengguna jasa. 
5. Menggunakan Container. $C$ ontainer adalah wadah yang dipakai sebagai tempat timbunan sampah, dimana penggunaannya bisa dilakukan secara individual atau secara bersama-sama (komunal).

- Peralatan sub-sistem pemindahan atau pengangkutan. Pada sub sistem ini, stasiun pemindahan (transfer depo atau transfer station), dimana fungsinya secara umum adalah sebagai tempat penampungan sementara (TPS) dan tempat bertemunya kendaraan pengumpul dengan kendaraan pengangkut.

- Peralatan sub-sistem pemilahan dan pengolahan Pemilahan dilakukan untuk menggolongkan jenis-jenis sampah sesuai dengan karakteristiknya, sehingga ketika masuk pada pengolahan. Menggunakan tenaga manusia (pemulung) atau menggunakan teknologi untuk mempermudah prosesnya. p. Pengolahan limbah padat dapat dilakukan dengan 2R (recycling, reuse).

1. Recycling adalah suatu proses pengolahan yang dilakukan dengan mengubah bentuk material sampah secara fisik dengan memproses kembali menjadi barang-barang yang berguna atau bermanfaat, seperti mengubah sampah plastik menjadi kursi plastik, ember plastik, dll.

2. Reuse adalah mengembalikan sampah menjadi barang berguna yang mempunyai manfaat yang sama seperti aslinya tanpa merubah identitasnya. Contohnya mengubah botol menjadi barang baru bernilai ekonomis.

\section{Implementasi}

Kebijakan Pengelolaan Limbah Padat Non B-3 Melalui Re-Use Atau Re-Cycling Untuk Kelestarian Lingkungan Hidup

Sejak diberlakukan nya peraturan daerah nomor 9 tahun 2007 tentang kebijakan pengelolaan limbah padat non B3 melalui re use dan re cyle kepada para pengelola limbah khususnya limbah padat non B3. Kebijakan ini membuat para pengelola limbah harus bijaksana dan mengikuti peraturan dengan tujuan sejak meningkatnya jumlah industri di 
Kabupaten Bekasi tentunya akan meningkat juga limbah yang dihasilkan terutama limbah padat non B3. Oleh karena itu melalui kebijakan ini diperlukan pengendalian yang dilakukan berupa perizinan dalam pengelolaan limbah padat non B3.

Pengelola limbah padat nonB3 yang semakin tidak terkendali jumlah nya di Kabupaten Bekasi menyebabkan lingkungan khususnya tempat umum menjadi tidak kondusif akibat penumpukan berupa barang limbah padat non B3 yang ditimbun oleh para pengelola limbah. Melalui kebijakan pengelolaan limbah padat non B3 para pengelola limbah harus turut serta mendaftarkan usaha nya sebagai izin perusahaan pengelolaan limbah kepada pemerintah daerah Kabupaten Bekasi. Selain sebagai izin pengelolaan limbah, kebijakan ini turut serta memberikan pembinaanpembinaan kepada para pengolah limbah untuk menjalankan usaha nya agar lebih terampil sehingga dapat menambah nilai guna suatu barang, khususnya didalam tata ruang lingkungan agar semakin baik, bersih dan bebas dari pencemaran limbah padat non B3 ini.

Melalui kebijakan pengelolaan limbah padat non B3 para pengelola limbah harus turut serta mendaftarkan usaha nya sebagai izin perusahaan pengelolaan limbah kepada pemerintah daerah Kabupaten Bekasi. Selain sebagai izin pengelolaan limbah, kebijakan ini turut serta memberikan pembinaan-pembinaan kepada para pengolah limbah untuk menjalankan usaha nya agar lebih terampil sehingga dapat menambah nilai guna suatu barang, khususnya didalam tata ruang lingkungan agar semakin baik, bersih dan bebas dari pencemaran limbah padat non B3 ini.

\section{Hasil Implementasi Kebijakan Pengelolaan Limbah Padat Non B-3 Melalui Re-Use Atau Re-Cycling Untuk Kelestarian Lingkungan Hidup}

Dalam hasil Implementasi Kebijakan Pengelolaan Limbah Padat Non B-3 Melalui Re-Use Atau Re-Cycling Untuk Kelestarian Lingkungan Hidup peneliti telah menyebarkan angket yang disebar secara acak kepada pemerintah daerah kabupaten Bekasi bagian Dinas Lingkungan dengan para pengelola limbah padat non B3 untuk mengetahui sejauh mana keberhasilan dalam pelaksanaan pengelola limbah non B3 untuk kelestarian lingkungan.

Dari hasil perhitungan skala presentase, diketahui jumlah hasil skala presentase hasil kebijakan pengelolaan 
limbah padat Non B3 melalui re-use dan re-cyling untuk kelestarian lingkungan adalah $87.8 \%$. Kriteria skala presentase yang dikonversikan dalam kualitatif adalah jika 0-40\% termasuk kategori rendah, 41$70 \%$ termasuk kategori sedang dan 71$100 \%$ termasuk kategori tinggi.

Hasil skala presentase tersebut menunjukan bahwa predikat hasil kebijakan pengelolaan limbah padat Non B3 melalui re-use dan re-cyling untuk kelestarian lingkungan adalah termasuk kategori tinggi.

Sebagai penguat hasil data skala presentase yang telah didapat, peneliti telah membuat tabel hasil rata-rata jumlah skor tiap butir soal didalam angket hasil kebijakan pengelolaan limbah padat Non
B3 melalui re-use dan re-cyling untuk kelestarian lingkungan yang telah dijawab oleh responden, seperti yang telah dijelaskan sebelumnya dalam

Dalam penelitian ini, peneliti menggunakan skala likert didalam angketnya dengan rentang 1-5. Jumlah skor yang tertinggi 5 dengan predikat sangat setuju dan jumlah skor terendah adalah 1 dengan predikat sangat tidak setuju. Adapun hasil rata-rata jumlah skor yang diperoleh dari angket hasil kebijakan pengelolaan limbah padat Non B3 melalui re-use dan re-cyling untuk kelestarian lingkungan sebagai berikut :

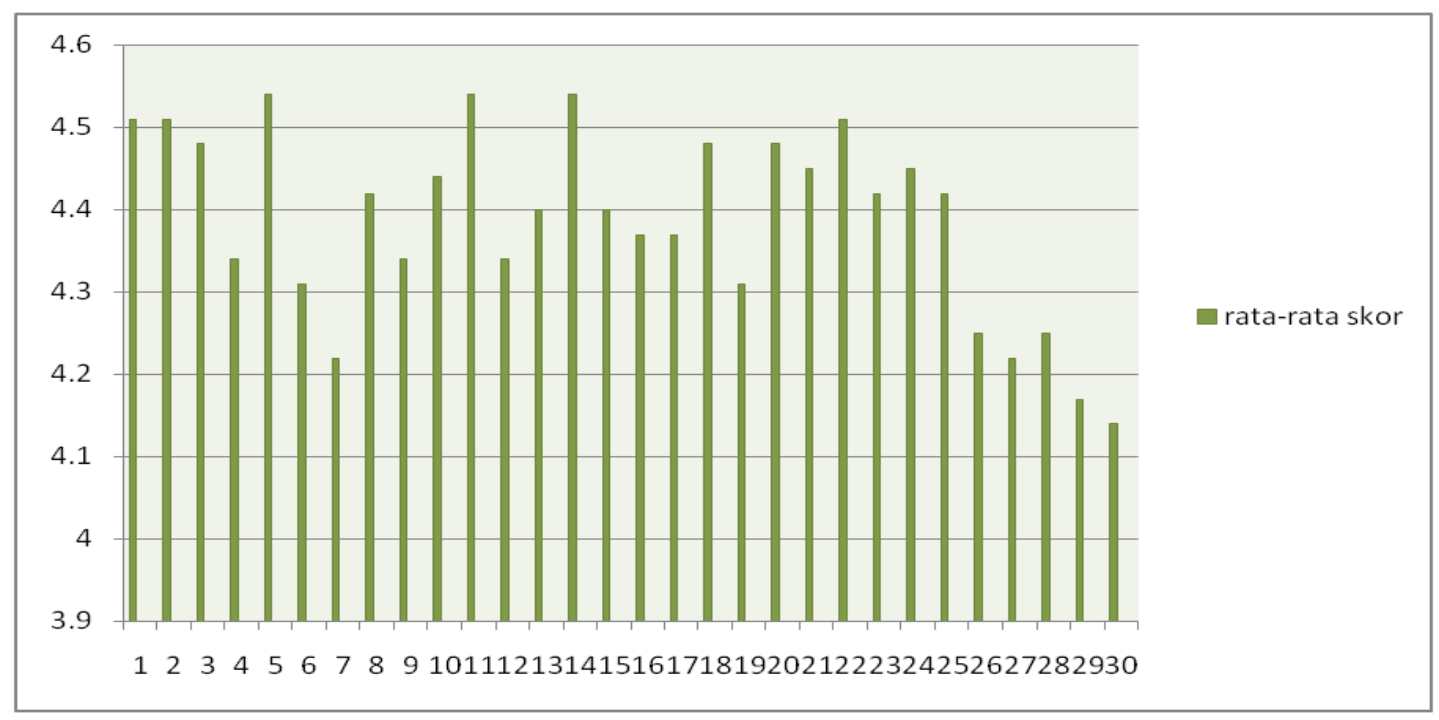

Gambar 1. Hasil Rata-Rata Jumlah Skor Yang Diperoleh Dari Angket Hasil Kebijakan Pengelolaan Limbah Padat Non B3 Melalui Re-Use dan Re-Cyling

Melalui hasil angket tersebut dengan semestinya seperti yang menunjukan bahwa kebijakan pengelolaan diharapkan bagi para pembuat kebijakan limbah padat Non B3 telah berjalan pengelolaan limbah khususnya limbah 
padat Non B3. Dengan adanya kebijakan pengelola limbah yang telah di berlakukan hingga saat ini, terdapat perubahan yang signifikan dengan kondisi lingkungan yang berada di kabupaten Bekasi. Lingkungan di Kabupaten Bekasi yang kian tertib dan bebas dari tumpukan tumpukan limbah padat non B3 yang belum di olah. Pengelola limbah yang telah terdaftar dan memperoleh perizinan telah mempersiapkan tempat untuk menampung limbah padat non B3 yang belum di olah sehingga tidak ada lagi tumpukan limbah yang berserakan.

\section{KESIMPULAN}

Melalui kebijakan pengelolaan limbah padat non B3 melalui re use dan re cyling untuk kelestarian lingkungan, telah mendapati hasil yang signifikan. Kondisi lingkungan khususnya di kawasan kabupaten Bekasi kini semakin kondusif dan bebas dari tumpukan-tumpukan limbah padat non B3 yang belum terolah dan tidak ditampung ditempat dalam kondisi tertib. Melalui kebijakan ini pun pemerintah mewajibkan untuk mendaftarkan dan mendapatkan perolehan izin bagi para pengelola limbah padat non B3 dari dinas pemerintah daerah bagian lingkungan. Hal tersebut menjadi sebuah keharusan agar tidak ada lagi para pengelola limbah khususnya limbah padat non B3 yang ilegal dalam mendirikan usaha. Pengelola limbah yang ilegal tidak memiliki ruang tempat khusus untuk menampung limbah padat non B3 yang belum di olah. Hal tersebut yang menjadikan kondisi di kawasan kabupaten Bekasi menjadi tidak kondusif dan tercemar.

\section{REKOMENDASI}

Pemerintah daerah kabupaten Bekasi seharusnya semakin memperbaharui kebijakan pengelolaan limbah khususnya limbah padat non B3 demi terciptanya kondisi lingkungan yang bebas pencemaran dan proses pengelolaan limbah yang kondusif. Pengawasan dari proses pelaksanaan kebijakan semakin di perhatian demi hasil evaluasi kebijakan pengelolaan limbah padat non B3 yang semakin baik di kawasan kabupaten Bekasi.

\section{DAFTAR PUSTAKA}

Damanhuri, E., \& Padmi, T. (2010). Pengelolaan sampah. Diktat Kuliah $T L, 3104$, 5-10.

Dunn, W. N. (2015). Public policy analysis. Routledge.

ELmakki, O. A. O. (2006). Challenges and 
possibilities of drip and canal irrigation in Northern Sudan. Master thesis). University of Life Sciences, Oslo, Norway.

Islamy, I. (1997). Prinsip-prinsip perumusan kebijaksanaan negara. Bumi Aksara.

Stanley, M. (2010). Sarah Maddison and Richard Denniss, An introduction to Australian public policy: Theory and practice. Dialogue E-Journal, 8(1), $1-2$. 